\title{
Children with Disabilities and Disaster Risk Reduction: A Review
}

\author{
Steve Ronoh $\cdot$ JC Gaillard $\cdot$ Jay Marlowe
}

Published online: 5 March 2015

(c) The Author(s) 2015. This article is published with open access at Springerlink.com

\begin{abstract}
Children with disabilities are often excluded from disaster risk reduction (DRR) initiatives and, as a result, can experience amplified physical, psychological, and educational vulnerabilities. Research on children with disabilities during disasters is lacking, and their potential value in helping shape inclusive policies in DRR planning has been largely overlooked by both researchers and policymakers. This article highlights the existing research and knowledge gap. The review includes literature from two areas of scholarship in relation to disasters-children, and people with disabilities - and provides a critique of the prevailing medical, economic, and social discourses that conceptualize disability and associated implications for DRR. The article analyzes the different models in which disability has been conceptualized, and the role this has played in the inclusion or exclusion of children with disabilities in DRR activities and in determining access to necessary resources in the face of disaster. Finally, the study explores possible pathways to studying the contribution and involvement of children with disabilities in DRR.
\end{abstract}

Keywords Children with disabilities - Disability concepts · Disaster risk reduction · Vulnerability

S. Ronoh $(\bowtie) \cdot$ JC Gaillard

School of Environment, The University of Auckland,

Auckland 1142, New Zealand

e-mail: sron443@aucklanduni.ac.nz

J. Marlowe

School of Counselling, Human Services and Social Work,

The University of Auckland, Auckland 1142, New Zealand

\section{Introduction: Children, Disabilities, and Disasters}

The United Nations Convention on the Rights of Persons with Disabilities (UNCRPD) adopted in 2006 was the first significant human rights instrument aimed at protecting and promoting the fundamental rights of persons with disabilities (UNCRPD 2006). This convention builds and elaborates on rights already set out in the World Programme of Action Concerning Disabled Persons of 1982, and the 1993 Standard Rules for the Equalization of Opportunities for Persons with Disabilities, among other United Nations (UN) human rights instruments (Barnes and Mercer 2001). The associated principles are based on respecting differences and accepting people with disabilities as part of a diverse human society. The Millennium Development Goals (MDGs) 2000, and the Hyogo Framework for Action (HFA) 2005-2015 policy frameworks also place emphasis on enhancing commitment to the management of risks and adopting a human rights approach. States would fulfill their obligations to respect, protect, and fulfill basic human rights, including the rights to safety of vulnerable people exposed to hazards.

The rise in the occurrence of disasters and their related impact on people is a growing concern in the international community. Yet, Smith et al. (2012) argue that the HFA and the latest MDGs 2012, for example, make no mention of the large number of children with disabilities who are out of school, and are also significantly affected by disasters (Peek and Stough 2010). According to the World Health Organization (WHO 2007), about $10 \%$ or 200 million of the world's children have a form of disability. These children often require additional educational and physical support and spend much of their school day under the direct supervision of a special educator (UNICEF 2007). Peek and Stough (2010) estimate that over seven 
million children annually are affected by disasters worldwide. Millions more acquire disabilities during childhood as a consequence of disasters (Peek and Stough 2010).

The disaster literature highlights the effects of natural hazards on children as a vulnerable group in society generally (Anderson 2005; Wisner 2006; UNICEF 2007; Peek 2008; MCDEM 2009; Gaillard and Pangilinan 2010). But researchers rarely examine the experiences of children with disabilities during disasters, regardless of their disability type (Peek and Stough 2010; Boon et al. 2011). As a result, children with disabilities are overlooked in DRR planning. The lack of research that focuses on children with disabilities, and their limited involvement with DRR planning, reinforces a sense that they are inherently vulnerable. Their knowledge is frequently derided as emotional and lacking validity (Crow 1996), and often perceived to have little to offer in terms of developing effective DRR.

A problem with effective inclusive participation in DRR is that people with disabilities are at the mercy of other people's "construction of what it means to have a disability" (Hodkinson 2007, p. 59). The term "children with disabilities," for example, is poorly articulated and means different things to different people (Aron and Loprest 2012). The lack of understanding and clarity on the use of the term partly contributes to the current exclusion of children with disabilities from participation in DRR activities. Consequently, the problems with the potential vulnerabilities of children with disabilities during disasters are poorly understood - the children are largely portrayed as "helpless" in the face of disaster (Hahn 1985; Smith et al. 2012; Aron and Loprest 2012). This article explores the existing research and knowledge gap related to policy and practice with respect to how children with disabilities are affected by disasters. Smith et al. (2012) pointed out that the potential value of children with disabilities in helping shape inclusive policies in DRR planning has been largely ignored by both researchers and policymakers. This article builds on Peek and Stough's (2010) pioneering work of a social vulnerability assessment and contributing vulnerability factors. It analyzes different models in which disability has been conceptualized and the role this plays in excluding children with disabilities in DRR activities and in determining access to necessary resources in the face of disaster. The following section first examines the concepts of vulnerability and disability, and discusses experiences of children with disabilities in disaster contexts.

\section{The Concept of Vulnerability in the Context of Disaster}

Disaster has been described in various ways by different researchers. However, the literature describing disasters has some common themes. They range from the suddenness of disasters and the inability of existing systems to cope, to widespread deaths, injuries, and economic losses, and lack of immediate access to livelihood resources. The literature also includes small or low-intensity and lingering events associated with droughts and conflicts (Peek 2008; Philips et al. 2010; Mutch 2013). For the purpose of this article, a disaster situation refers to a natural hazard that has consequences in terms of damages, livelihood/economic disruptions, and/or casualties that are too great for the affected area and people to deal with adequately on their own (Wisner et al. 2012).

The concept of vulnerability has been the subject of intense debate and interpretation among various schools of thought. The concept is often used in divergent ways, for different purposes (Bankoff et al. 2004), and sometimes out of its original theoretical framework; vulnerability is viewed as a social construct associated with fragility in the face of natural hazard (Gaillard 2010). Peek (2008) notes that previous research attributes vulnerability and exposure to natural hazards to intersections between key environmental and social indicators that include: the quality of human settlements and the built environment, socioeconomic status, gender, race, ethnicity, age, disability and health status, occupation, education, access to resources, social networks, and social dependence. In the disaster context, the term vulnerability has been used to refer to susceptibility to suffer damage in a potentially dangerous natural event (Gaillard 2010). The term denotes the degree to which one's social status (for example, culturally and socially constructed in terms of roles, responsibilities, rights, duties, and expectations concerning behavior) influences differing effects of natural hazards and the social processes that lead to and maintain that status (Wisner et al. 2012).

From that viewpoint, both disaster researchers and practitioners identify children, the elderly, women, racial and ethnic minorities, the poor, persons with disabilities, and immigrants as especially vulnerable to the harmful effects of disasters (Wisner et al. 2004; Kailes and Enders 2007; Philips et al. 2010). Additionally, the implication is that individuals and communities may be vulnerable geographically because they often live in hazardous places (for example, coastal zones, seismic areas) due to lack of better access to land, and may be poor, lacking the resources to invest in protective measures, and lacking the savings to face crises. People may be vulnerable socially because they are part of a minority group, have limited access to social protection, and have weak social networks (Wisner et al. 2004).

Vulnerability accrues from the various components that comprise a given society - the social, economic, and political structures or systems. These can make hazard 
occurrences a crisis or disaster (Wisner et al. 2004). Vulnerability is attributed to limited or no access to vital dayto-day resources, and poor and unstable access to resources results in marginalization in daily life and in facing natural hazards (Gaillard and Maceda 2009). The root causes of vulnerability stem from social structures that can be traced historically to explain the ideological and cultural assumptions that give those structures their perceived legitimacy (Wisner et al. 2012). These structures determine both the availability of and access to resources, and the means of protection in DRR. Consequently, the lack of access to vital day-to-day resources-natural, social, economic, physical, and human-often undermines the required capacity in the face of a disaster and for coping and recovering in its aftermath (Wisner et al. 2012). The following section describes how children with disabilities face disaster and identifies how potential vulnerabilities are largely determined by access to necessary resources and assets.

\section{Children with Disabilities and Their Experiences of Disasters}

The literature on disasters suggests that children are a vulnerable group and often disasters have occurred when the children are in school (King et al. 2003; Peek and Stough 2010; Boon et al. 2011). Some examples include the 2001 Gujarat earthquake in India, the 2005 Kashmir earthquake, and the 2008 Wenchuan earthquake in Sichuan, China, where school children were killed or injured in large numbers (UNICEF 2010). The Wenchuan earthquake struck during the early afternoon on a weekday, when effectively every school-aged child in Sichuan Province was in a classroom. This earthquake damaged or destroyed 12,000 school buildings in Sichuan Province and 6500 school buildings in Gansu Province, disrupting the education of some 2.5 million children (Peek 2008; UNICEF 2010).

Similarly, in New Zealand the 2011 Christchurch earthquake occurred at 12:51 p.m., a time when all children are expected to be in school. Effects included school closures, demolitions, power cuts, and the establishment of temporary school sites following the earthquake (Mutch 2013). Although specific research on the disaster effects on children with disabilities and schools is lacking, the timing of many disasters means that these children can be significantly affected.

Disaster researchers agree that, for children with disabilities, vulnerability in facing natural hazards can be exacerbated by factors that include mobility difficulties, preexisting medical conditions, and existing social and physical structures and policies (King et al. 2003; Peek and
Stough 2010; Boon et al. 2011). Some children with disabilities may have preexisting medical conditions, suffer from life-threatening consequences due to separation from caregivers, and be prone to illness, malnutrition, and abuse when disaster strikes (Boon et al. 2011). They may acquire additional impairments and experience additional health issues as a result of inadequately staffed shelters that are not prepared to meet their medical needs (Lemyre et al. 2009). Children with autism-spectrum disorders have sensory integration problems that may include high sensitivity to light, sounds, odors, tastes, and touch making them particularly vulnerable during disasters (Boon et al. 2011).

Physical disabilities can limit children's effective responses to disaster. For example, none of the 700 people with post-polio paralysis on an island of the Andaman archipelago in the Bay of Bengal survived the 2004 tsunami because they were unable to run to the top of the surrounding hills (Hans et al. 2008; Alexander et al. 2012). Children with disabilities in schools managed by an Indonesian society caring for children with disabilities in Banda Aceh were all killed as well by the same tsunami (CIR 2005). In Haiti, a country where people with disabilities are commonly known as "Kokobes" ("good for nothings"), hundreds of children lost their limbs from crashes during the 2010 earthquake, while others underwent amputation as a result of secondary infections (Alexander et al. 2012).

Reviewing existing literature on children with disabilities, Peek and Stough (2010) identified some of the common risk factors in children with disabilities that increase the probability of negative physical effects on these children during disasters. These include the likelihood that they live in poverty and in low-cost and lower-quality housing that is more prone to damage or collapse. Murray (2011) also noted that these children, especially in less affluent countries, grow up in communities affected by poverty, live in below-standard housing, and are left without the resources to evacuate when disasters strike. This consideration is particularly important given that sudden-onset hazards like tornadoes and earthquakes give little warning to allow those with disabilities to take recommended protective actions or escape, particularly children with mobility limitations (Peek and Stough 2010).

Limited language proficiency, both oral and written, is also common for children with disabilities (Murray 2011). Children with hearing difficulties are disadvantaged when oral directions are given unaccompanied by sign language. This can affect how quickly a child becomes aware of an (impending) disaster, their access to emergency information during a disaster, and their ability to ask for assistance (Campbell et al. 2009; Boon et al. 2011). In Galle, Sri Lanka, for example, only 41 out of 102 residents of a home for people with disabilities survived the 2004 tsunami. 
According to the International Federation of Red Cross and Red Crescent Societies (IFRC 2007), the residents were either unable to leave or failed to understand the need to evacuate in time.

Social distancing or stigma associated with the label "disabled" may further limit access to vital resources, social networks, and other sources of psychological support during a disaster, or make it difficult for a child with a disability to adjust emotionally to a new neighborhood or community (Tierney et al. 1988). Families caring for children with disabilities remain vulnerable in facing disaster because disabilities are strongly associated with social, structural, and financial disadvantage (AIHW 2009). Boon et al. (2011) also maintain that children with disabilities are more likely to experience intra- and extrafamilial abuse and neglect generally, a risk that is particularly amplified during a disaster and its aftermath (AIHW 2009). Children with disabilities, who may already have limited social networks, are often separated from caregivers during a disaster. This deprives the children of critical information and support, and disrupts the continuity of medical care (Baker et al. 2012).

Another crucial factor is that people and children with disabilities are often overlooked during emergency preparations and in DRR policy at large, leaving them unprepared for emergency. The lack of knowledge about disabilities is intrinsically linked to the exclusion of people with disabilities from DRR activities (Smith et al. 2012). They are without a "political voice" and this means that their views and the issues that characterize children with disabilities are not considered (Wisner et al. 2004; Anderson 2005). This neglect of people and children with disabilities in emergency preparation limits their capacity to effectively participate and contribute to society. Wisner (2002, p. 4) argued that:

[...] at the heart of the disability rights movement have been legal challenges to the lack of "access" and "equal opportunity" in a world that had constructed itself around the abilities and needs of people without impairments in mobility, hearing, sight, speech, stamina, cognition, mental or emotional stability.

Admittedly, an increasing amount of work has been directed at researching disaster experiences of children and youth generally, not only research for or with children but also by children (Save the Children 2006; Stough 2009; Peek and Stough 2010; UNICEF 2010; Mutch 2013). Examples have emerged internationally of children's capacity to actively contribute to planning, preparedness, response, and recovery efforts, and the apparent positive mental health benefits of these involvements (Save the Children 2006; Wisner 2006; Mutch 2013). Research on disabilities and disasters, however, has only focused on adult populations (Stough 2009; Handicap International 2009; MCDEM 2013). In response to the 2011 Christchurch earthquake in New Zealand, for example, the government published an important document Including People with Disabilities (MCDEM 2013), but this document only focuses on adults with disabilities. Two research parallels have since emerged: one that focuses on children and another that focuses on adults with disabilities. This leaves a knowledge gap in-between of the experiences of children with disabilities in disasters (Peek and Stough 2010).

Although there is evidence suggesting that children are being increasingly involved in DRR decision making, growth has been slower with respect to children with disabilities (Franklin and Sloper 2009). The literature shows that many organizations have, in theory, produced sound policies and procedures that acknowledge the need to involve children in decision making; but little or no change has occurred in practice. Turnbull et al. (2001) and Priestley and Hemingway (2007) have aptly summed up the situation that laws are created and remain on paper, "that is to say statutes and cases create claims to certain kinds of services, but they do not themselves ensure that services are delivered" (Turnbull et al. 2001, p. 143). In practice, policy and planning continues to remain at "helping the disabled" individual to adjust and accept the existing environment, rather than altering the environment to accommodate the needs of individuals with disabilities (Hahn 1985; Kailes and Enders 2007).

This situation creates an urgent need for evidence-based research to explore the experiences of children with disabilities in disasters, and the role disability conceptualization plays in overlooking their capacity and potential contribution to DRR. Addressing this largely neglected focus will allow planners to consider the needs of children with disabilities in DRR initiatives.

\section{Conceptualizing Disability}

The way disability has been conceptualized and poorly articulated exposes a persistent lack of clarity and understanding of the terminology (Hodkinson 2007; Aron and Loprest 2012). Consequently, the exclusion of people with disabilities from participation in DRR activities is partly due to the lack of a clear and consistent articulation of the terminology. The term "disability" is broad, with varying taxonomies that are socially constructed and defined by medical, economic, and social assessments and discourses (Bankoff et al. 2004; Birkman 2006; Peek and Stough 2010; Watson et al. 2012). All three approaches to conceptualizing disability can negatively affect DRR.

The medical model approach views disability as a natural consequence of impairment rather than a condition 
caused by society. This standpoint ignores structural and cultural barriers that block the inclusion of children with disabilities in disaster preparedness initiatives. Priestley (1998) argued that professionals give more attention to measuring children's bodies and minds, and less to facilitating their inclusion into society. The limitation of the medical model approach is its preoccupation with "inability" or "limitations" of individuals without due considerations to modifying the physical environment, changing occupational "roles and tasks," or altering the expectation that all men and women are required to possess a full range of physical, mental, and environmental capacities to qualify for membership in the human community (Hans et al. 2008). The demand appears to be for people with disabilities to adapt and adjust to the surroundings without imposing a corresponding obligation on policymakers to create an environment that can accommodate the needs and desires of people with disabilities (Watson 2012).

The economic model of disability focuses on the economic problem of unemployment and the associated costs of disability, placing primary emphasis on physical functioning. The approach suggests that disability can be described as a "health-related inability" or limitation on the amount or kind of work that can be performed (Hans et al. 2008). This viewpoint has been widely adopted in public policy-related issues, and seems to reflect the prevalent tendency in an industrialized society to stipulate physical capabilities as occupational requirements (Hahn 1993). This model might be appropriate where an economy is solely based on manual labor rather than on the contemporary delivery of services and involvement in high technologies. There is a biased focus towards "roles and tasks" associated with work to the exclusion of other rights and responsibilities, or their capacities. Watson et al. (2012) underscore the expectation that individuals with disabilities need to fulfill existing requirements for employment, without the option or possibility of altering the job expectations to accommodate the needs and skills of employees with disabilities.

The social model is informed by the idea that disability is centrally structured by social oppression, inequality, and exclusion (Thomas 2004) and is viewed alongside sexism, racism, and other discriminatory practices (Watson et al. 2012). This approach views disability as stemming from the failure of a structured social environment to adjust to the needs and aspirations of citizens with disabilities, rather than from individual failings or inabilities to adapt to societal demands (Hans et al. 2008). The social model is explicitly committed to assisting people with disabilities in their fight for full equality, social inclusion, participation, and involvement in community activities (Crow 1996). Significantly, this model argues that disability is not due to impairment, but rather is caused by barriers erected by a disabling society through collective thinking and action (Thomas 2004).

Disability scholars concur that no model, including the social model, can totally explain disability (Pfeiffer 2001). Acknowledging the causal link between impairment and disability offers a significant point of convergence between the models. Therefore, a possible way forward is incorporating the medical model's view that impairment and illness have disabling effects (Crow 1996; Thomas 2004) and the social model's view that urges the integration of people with disabilities into the community as a more equitable and practical alternative to exclusion (Pfeiffer 2001), and thus promotes their involvement in DRR. Since there is no single DRR strategy suitable for all types of disabilities (Kailes and Enders 2007), some researchers propose a functional-needs approach of defining disability in disaster. This would be an approach that highlights the support the individual may need in areas of communication, medical care, functional independence, supervision, and transportation (Kailes and Enders 2007). Such an approach is particularly useful in the vulnerability and capacity assessment in the face of disaster, a concept discussed in the next section.

\section{The Concept of Capacity in the Context of Disaster}

Another key concept is capacity, which Cadag and Gaillard (2014) define as the set of knowledge, skills, and resources people resort to in dealing with natural hazards and disasters. Individuals and communities have generally developed intrinsic abilities to learn and adjust, using different skills and sources of knowledge and self-organization, and involving social networks and institutional linkages that help them in the face of disaster (Haque and Etkin 2007). Coping mechanisms and other strategies used to face natural hazards are usually rooted in people's everyday livelihoods (Haque and Etkin 2007). More importantly, the emphasis is that capacities not only refer to available resources but more crucially to their access. Kuban and Mackenzie-Carey (2001) pointed out that the capacity concept encompasses the ability to either use or access the resources needed. The concept therefore goes beyond the availability of resources and is not the opposite of vulnerability on a single, linear spectrum (Wisner et al. 2012).

Capacities are often rooted in resources and assets that are largely endogenous to the community facing hazards. In contrast, vulnerability emphasises structural constraints which are often exogenous to the community and include inequalities in distribution of power and wealth as well as the structure of local and global social and political systems 
(Gaillard 2010). The endogenous nature of resources that compose capacities (for example, local and/or indigenous knowledge and networks) makes it easier to enhance the production and formation of individual and collective capacities than to reduce vulnerabilities. It encompasses participating in activities, often at the household, school, or community level, which strengthens people's strategies for facing the occurrence of natural hazards. Examples include agreeing on warning signals for potential hazards and associated protective actions, planning evacuation routes and meeting points, identifying vehicles and shelters, and preparing emergency kits and resources to cope with the disruption of daily life (Wisner et al. 2012).

For children with disabilities, access to vital day-to-day resources ultimately determines their ability to face a disaster. However, it may not be practical to place a clear boundary around the child when describing access to resources, and the associated level of involvement. McConachie and Diggle (2007) argued that often child participation and experiences occur as part of a family, school, or community with adult support. Possible pathways towards studying and linking capacities and the potential contribution to DRR need to be explored and challenges to their involvement identified. For example, the existing heterogeneity among children with disabilities implies a wide array of potential capacities alongside an awareness of vulnerabilities that need to be explored.

\section{Next Steps: Exploring Children with Disabilities' Potential Contribution to Disaster Risk Reduction}

Despite researchers acknowledging that children with disabilities have not been actively involved in DRR planning (Peek and Stough 2010; Boon et al. 2011; Alexander et al. 2012), few studies have assessed the perceived barriers to children with disabilities' involvement in school or community activities (Law et al. 2007; Franklin and Sloper 2009). This lack of information about and meaningful engagement with children who have disabilities creates additional barriers to their participation in DRR planning. Peek (2008) outlined three ways in which children generally can be involved in DRR activities. They include preparing for disaster through school-based hazard education programs and sharing children's understanding within the community to increase accurate knowledge of hazards and the required risk reduction strategies. The second way is to promote children's involvement in responding to disaster; Peek (2008) provided examples of children who warned and convinced their own families and tourists of the impending tsunami threats in Thailand in 2004. Third is the children's involvement in recovery and the recovery of those around them.
Nonetheless, researchers realize that research on children with disabilities remains complex due to the diverse ways in which disability is conceptualized and the children's depiction as "helpless" in disaster (Hahn 1985; Aron and Loprest 2012). This perception is a cultural construction of incompetence and dependence that masks the children's actual capacities (Woodhouse 2004). On the contrary, almost everyone, including children with disabilities, usually has some capacity for self-protection and group action. Children possess the capacity to resist, avoid, and adapt to the processes of disaster preparation and response, and to use their abilities for creating security, either before a disaster occurs or during its aftermath (Wisner et al. 2012).

A review of the daily experiences of children with disabilities (Heah et al. 2007) highlighted their potential capacities (both individual and collective) during disaster. Even when directly affected by disaster, children can and often do cope effectively with disruptive shocks, especially with appropriate support from parents/caregivers and when living in a safe and nurturing environment (Peek and Stough 2010). In addition many schools offer both formal and informal DRR activities. When children receive information about hazard risks they can share their knowledge with their families and communities (Wisner 2006), and ultimately prompt positive change and realistic risk perceptions (Peek 2008). They can also be role models, motivators, and resource persons for those newly injured in a disaster (Handicap International 2009).

Children with disabilities negotiate altered and sometimes difficult physical and environmental limitations on a daily basis (UNISDR 2013). Thus, they often operate with heightened complementary senses (for example, individuals who are blind develop an acute sense of hearing). Some people with disabilities have enhanced tactile sense and are often able to navigate in the dark; this provides them with a "psychological advantage" that makes them less likely to become injured or to panic during and after a disaster (UNISDR 2013, p. 28). The counterargument is that persons with certain types of impairments are more prone to stress in altered environments unfamiliar to them (UNISDR 2013). This calls for research that engages children who have diverse disabilities and identifies their potential role in DRR.

Children with disabilities are knowledgeable and can be innovative and creative in times of disaster (James and Prout 1990; Bender et al. 2007; Peek 2008). They should be viewed as actively involved in the construction of their own life (and the lives of those around them). Different children use or give different meaning to the same cultural artefacts (James and Prout 1990). For example, they can be involved in school hazard identification and mapping, or other DRR activities. Although in the social context, 
parents can sometimes provide insight into their child's situation, Garth and Aroni (2003) insisted that children's understanding and experience of the world is different from that of their parents and that children with disabilities are able to identify "good practice" too. They are resourceful in their schools and communities, and have the capacity to influence family members and friends as valuable risk communicators (Peek 2008). However, while disasters often harm their physical spaces-where they live, learn, and play-they are rarely involved in the process of rebuilding these spaces.

A point of convergence among researchers is the acknowledgment that children's involvement in structured school or community activities reduces behavioral and emotional problems, particularly in children living in highrisk environments, for example, poverty-ridden and highcrime neighborhoods (Law et al. 2007; Boon et al. 2011). Mutch (2013) proposed a continuum of engagement of children in research on, about, with, and by children, while Peek and Stough (2010) emphasized the need for their active involvement and consideration in all DRR activities to mitigate disaster effects. Useful DRR programs can involve children in mapping risks in their school, and undertaking hazard minimization strategies and disaster simulation (Wisner 2006; Mutch 2013). Participation in such activities provides children with the challenge to not only come up with local solutions, but to recognize and seek necessary external support. That means that some of the activities they may participate in could include identifying evacuation routes and equipment, potential hazards, alert and communication methods, and as trained assistants for individuals with disabilities. The advantage is that schools have been found to encourage participation by promoting caring relationships, buddy systems among peers, and welcoming attitudes (Law et al. 2007; Mutch 2014). This positions schools as strategic entry-points for research that involves the role of children with disabilities in the DRR agenda (Wisner 2006).

\section{Obstacles to Involving Children with Disabilities in Disaster Risk Reduction}

Recent disasters have revealed complexities in the associated responses when considering the needs of potentially vulnerable populations (Redlener 2008; Baker et al. 2012). Research suggests that people differ significantly in their degree of vulnerability to natural hazards (Anderson 2005), and this subsequently influences their level of involvement in DRR. Experts argue that significant inequality exists in vulnerability levels even when the physical dimensions of particular threats are similar (Cannon 1994; Anderson 2005; Peek and Stough 2010). Wisner et al. (2012) broadly attributed vulnerability to poor and unstable access to resources resulting in marginalization in daily life and in facing natural hazards. Inequitable distribution of resources within the society is largely determined by historical social structures, and the ideological and cultural assumptions giving those structures their perceived legitimacy. These are structures that in effect are the root causes of vulnerability.

Those marginalized and vulnerable in facing hazards are often also those who struggle in the aftermath of disasters. The financial burden of caring for people with disabilities is carried by families and local communities. Families caring for children with a disability are associated with social, structural, and financial disadvantages and low incomes (AIHW 2009; Peek and Stough 2010; Alexander et al. 2012). Disability overlaps the clusters referred to as "class" and "age" and the vast majority of people with disabilities are also poor (Wisner et al. 2012). Moreover, those with serious health conditions may have limited social networks and higher dependency for external assistance in a disaster situation. Without appropriate intervention from the authorities and supporting organizations, people with disabilities can have amplified vulnerabilities in disaster contexts and diminished capacities (Gaillard and Cadag 2009). Specific to children with disabilities, their age intersects with other personal and social characteristics, such as their geographical location, family structure, socioeconomic status, physical and mental abilities, culture, stage of development, and nationality. These characteristics determine both the likelihood of harm in a particular disaster and their link to potential challenges with respect to the children's involvement in DRR.

Overlooking children with disabilities in DRR activities significantly contributes to their vulnerability. Their involvement in school and community activities, for example, is often hampered by one or a combination of factors that may include children having very limited or no use of speech or being seen as having high or multiple levels of impairment. However, Franklin and Sloper (2009) noted that little effort is made to find alternative methods of communication. While researching children with visual impairments and their comprehension of surrounding space, Andreou and McCall (2010) described them as part of a population that is very heterogeneous and often cannot be classified into a single group or category. Even specific impairments - such as visual and hearing impairmentsrange in severity from mildly impaired to totally blind or profoundly deaf (Odom et al. 2005). This implies the need to consider a wide array of vulnerabilities and capacities based on access to resources in relation to DRR planning. A starting point for involving children with disabilities in DRR initiatives is researching their experiences in the face 
of disaster, and subsequently designing policies that consider their potential contribution.

Involving children in a decision-making process takes time and slows down the process. It involves adults and children developing new skills, requires investment of resources, and often entails a major shift in attitude within organizations and in power relations where children are viewed as incompetent and in need of protection (Franklin and Sloper 2009), instead of providing them with access to resources. At one level, one may agree with the argument not to expect young children and, more so, those with disabilities, to understand complex decision-making processes, thus raising important issues to ponder. However, the United Nations Convention on the Rights of the Child acknowledges that "children hold the right to express their opinion about issues affecting them and to have their views heard" (Hodkinson 2007, p. 70). Mahon et al. (1996) observed that valid accounts of children's experiences require direct engagement with the children and treating them as independent actors. This statement does not take away the concern over their capability-for example, of children with cognitive impairment - to be actively involved and to be able to understand concepts of decision making. The process of weighing options and choosing abstract concepts and time frames (Franklin and Sloper 2009) is often required in DRR planning. There is a need for research that explores the complex array of diverse disabilities to capture insights, realities, obstacles, and potentials for involvement.

Mahon et al. (1996) argued that, because children are perceived as vulnerable and not competent, this justifies the use of proxies as children's representatives to articulate their issues (Mahon et al. 1996, p. 145). Anderson (2005) contended that DRR research on children with disabilities has lagged behind, mainly as a result of their status in society. Children with disabilities are seen as unable to make choices and require their lives to be structured and controlled by adults (Watson et al. 2012). Shakespeare and Watson (1998) argued that traditional approaches in social work, health, and education tend to concentrate on children with disabilities' "need for care," highlight their "dependent" status, and emphasize their vulnerability. These attitudes and the lack of social support-including bullying, social segregation, and marginalization-remain potent barriers to the children's participation, thus making them isolated and wary of participation in school and community events (Law et al. 2007).

Researchers have also identified the physical environment as a limitation to effective involvement of children with disabilities. Findings by King et al. (2003) suggested that the physical environment has historically been influenced by the characteristics or needs of persons without disabilities. Watson et al. (2012) pointed out that although aspects of the environment including architecture, communications, and other settings offer a context for social interaction, they are fundamentally molded by public policy. These environments often possess inherent adult designs and values and remain restrictive to children with disabilities who encounter restricting physical environments and find themselves unable to integrate into the broader community (Thompson and Philo 2004). Hans et al. (2008) observed that the solution to the problems posed by disability must be achieved by policy changes that affect the environment, rather than by an exclusive reliance on alterations of the functional or economic capabilities of individuals with disabilities. In the same vein, questions need to be asked about whether disaster preparedness policies reflect only adult expectations without regard to children's viewpoints and hence affect the children's contribution to DRR. Deeper understandings of these issues, informed by children's voices, can give policymakers and practitioners the opportunity to design appropriate interventions in DRR initiatives.

\section{Conclusion}

The limited research focused on children with disabilities during disasters highlights a pressing need for further study to assess and understand effective pathways for ensuring active participation of children with disabilities, both at school and in the community (Mihaylov et al. 2004). No field research specific to the experiences of children with disabilities in response to disaster has been undertaken (Peek and Stough 2010; Boon et al. 2011). Children with disabilities have been overlooked in DRR initiatives and may also have difficulties obtaining access to resources in the face of disasters, thus making them potentially vulnerable when facing natural and other hazards.

This article has reviewed the concepts of vulnerability, disability, and capacity, which are interconnected in determining access, or its lack, to resources vital for DRR. It has critiqued the different ways in which disability is conceptualized and argues that the medical, economic and, to a lesser extent, social model of conceptualization play a role in excluding children with disabilities in DRR initiatives. This exclusion, together with the vulnerability that stems from social, political, and economic structures/systems, limits their access to necessary resources required in facing disaster (Hans et al. 2008; Wisner et al. 2012).

The article notes the capacity concept's emphasis on access to resources and assets needed during a disaster (Wisner et al. 2004). The argument is that capacities are often rooted in resources that are largely endogenous to the community facing hazards, as opposed to vulnerability. Therefore there is need for researchers and planners to recognize these capacities in strengthening people's strategies in the face of a disaster (Gaillard 2010). The 
larger problem, however, is that prevailing discourses on disability and vulnerability are often focused on individuals rather than on structure. There is little structural will to address the implications of DRR for children with disabilities because they are rendered largely invisible by the society and its economically fundamentalist social policies. It is therefore important for disaster researchers to first identify and recognize the capacities specific to children with disabilities to enable DRR planners to develop strategies that make use of these capacities.

For children with disabilities, an opportunity for their inclusion in DRR initiatives would enhance their participation and their capacity to face and contribute during a disaster. Understanding context-specific vulnerabilities and capacities can help researchers, educators, communities, policymakers, and families to develop targeted strategies for promoting involvement (Law et al. 2007), and strengthen their role in DRR. This kind of information will also contribute to the body of knowledge and a significant understanding of effective strategies for mitigating disaster risks.

Many planners tend to overlook people's experiences of disaster and the different strategies they use to cope with and respond to disasters within the recovery process. An understanding of the experiences of children with disabilities remains the first step towards their involvement in DRR initiatives. This review specifically reinforces the need for disaster research that directly engages children with disabilities, and obtains their perspectives in DRR planning, something currently invisible in academic literature.

Open Access This article is distributed under the terms of the Creative Commons Attribution License which permits any use, distribution, and reproduction in any medium, provided the original author(s) and the source are credited.

\section{References}

AIHW (Australian Institute of Health and Welfare). 2009. A picture of Australia's children 2009. Canberra: PHE 112, AIHW.

Alexander, D., J.C. Gaillard, and B. Wisner. 2012. Disability and disaster. In Handbook of hazards and disaster risk reduction, ed. B. Wisner, J.C. Gaillard, and I. Kelman, 413-423. London: Routledge.

Anderson, W.A. 2005. Bringing children into focus on the social science disaster research agenda. International Journal of Mass Emergencies and Disasters 23(3): 159-175.

Andreou, Y., and S. McCall. 2010. Using the voice of the child who is blind as a tool for exploring spatial perception. British Journal of Visual Impairment 28(2): 113-129.

Aron, L.Y., and P.J. Loprest. 2012. Meeting the needs of children with disabilities. Washington, DC: Urban Institute Press.

Baker, M.D., L.R. Baker, and L.A. Flagg. 2012. Preparing families of children with special health care needs for disasters: An education intervention. Social Work in Health Care 51(5): 417-429.

Bankoff, G., G. Frerks, and D. Hilhorst. 2004. Mapping vulnerability: Disasters, development, and people. London: Earthscan.

Barnes, C., and G. Mercer. 2001. Disability culture. In Handbook of disability studies, ed. G.L. Albrecht, K.D. Seelman, and M. Bury, 515-534. London: Sage.

Bender, K., S.J. Thompson, H. McManus, J. Lantry, and P.M. Flynn. 2007. Capacity for survival: Exploring strengths of homeless street youth. Child \& Youth Care Forum 36(1): 25-42.

Birkman, J. (ed.). 2006. Measuring vulnerability to natural hazards. Tokyo: United Nations University Press.

Boon, H.J., L.H. Brown, K. Tsey, R. Speare, P. Pagliano, K. Usher, and B. Clark. 2011. School disaster planning for children with disabilities: A critical review of the literature. International Journal of Special Education 26(3): 223-237.

Cadag, J.R.D., and J.C. Gaillard. 2014. Integrating people's capacities in disaster risk reduction through participatory mapping. In Disaster management: International lessons in risk reduction, response and recovery, ed. A. Lopez-Carrresi, M. Fordham, B. Wisner, I. Kelman, and J.C. Gaillard, 269-286. London: Earthscan.

Campbell, V.A., J.A. Gilyard, L. Sinclair, T. Sternberg, and J.I. Kailes. 2009. Preparing for and responding to pandemic influenza: Implications for people with disabilities. Journal Information 99(2): 294-300.

Cannon, T. 1994. Vulnerability analysis and the explanation of "natural" disasters. In Disasters, development and the environment, ed. A. Varley, 13-30. Chichester: Wiley.

CIR (Center for International Rehabilitation). 2005. International disability rights monitor: Disability and early tsunami relief efforts in India, Indonesia and Thailand. Chicago: International Disability Network.

Crow, L. 1996. Including all of our lives: Renewing the social model of disability. In Exploring the divide, ed. C. Barnes, and G. Mercer, 55-72. Leeds: The Disability Press.

Franklin, A., and P. Sloper. 2009. Supporting the participation of disabled children and young people in decision-making. Children and Society 23(1): 3-15.

Gaillard, J.C. 2010. Vulnerability, capacity and resilience: Perspectives for climate and development policy. Journal of International Development 22(2): 218-232.

Gaillard, J.C., and J.R.D. Cadag. 2009. From marginality to further marginalization: Experiences from the victims of the July 2000 Payatas trashslide in the Philippines. JAMBA: Journal of Disaster Risk Studies 2(3): 197-215.

Gaillard, J.C., and E.A. Maceda. 2009. Participatory three-dimensional mapping for disaster risk reduction. Participatory Learning and Action 60(1): 109-118.

Gaillard, J.C., and M.L.C.J.D. Pangilinan. 2010. Participatory mapping for raising disaster risk awareness among the youth. Journal of Contingencies and Crisis Management 18(3): 175-179.

Garth, B., and R. Aroni. 2003. "I value what you have to say". Seeking the perspective of children with a disability, not just their parents. Disability and Society 18(5): 561-576.

Hahn, H. 1985. Toward a politics of disability: Definitions, disciplines, and policies. The Social Science Journal 22(4): 87-105.

Hahn, H. 1993. The political implications of disability definitions and data. Journal of Disability Policy Studies 4(2): 41-52.

Handicap International. 2009. Mainstreaming disability-People with disability into disaster management in nepal. 2009 report. http:// www.Handicap-International.fr/fileadmin/.../DisasterRiskReduc. Pdf. Accessed 25 Aug 2013.

Hans, A., A.M. Patel, R.K. Sharma, D. Prasad, K. Mahapatra, and R. Mohanty. 2008. Mainstreaming disability in disaster 
management: A tool kit. New Delhi: United Nations Development Programme.

Haque, C.E., and D. Etkin. 2007. People and community as constituent parts of hazards: The significance of societal dimensions in hazards analysis. Natural Hazards 41(2): 271-282.

Heah, T., T. Case, B. McGuire, and M. Law. 2007. Successful participation: The lived experience among children with disabilities. Canadian Journal of Occupational Therapy 74(1): 38-47.

Hodkinson, A. 2007. Inclusive education and the cultural representation of disability and disabled people: Recipe for disaster or catalyst of change? An examination of non-disabled primary school children's attitudes to children with disabilities. Research in Education 77(1): 56-76.

IFRC (International Federation of Red Cross and Red Crescent Societies). 2007. World disaster report: Focus on discrimination. Geneva: IFRC.

James, A., and A. Prout (eds.). 1990. Constructing and reconstructing childhood: Contemporary issues in the sociological study of childhood. London: Falmer.

Kailes, J.I., and A. Enders. 2007. Moving beyond "special needs" A function-based framework for emergency management and planning. Journal of Disability Policy Studies 17(4): 230-237.

King, G., M. Lawm, S. King, P. Rosenbaum, M.K. Kertoy, and N.L. Young. 2003. A conceptual model of the factors affecting the recreation and leisure participation of children with disabilities. Physical and Occupational Therapy in Pediatrics 23(1): 63-90.

Kuban, R., and H. MacKenzie-Carey. 2001. Community-wide vulnerability and capacity assessment (CVCA). Ottawa: Office of Critical Infrastructure Protection and Emergency Preparedness.

Law, M., G. King, S. King, M. Kertoy, P. Hurley, P. Rosenbaum, N. Young, and S. Hanna. 2007. Patterns of participation in recreational and leisure activities among children with complex physical disabilities. Developmental Medicine and Child Neurology 48(5): 337-342.

Lemyre, L., S. Gibson, J. Zlepnig, R. Meyer-Macleod, and P. Boutette. 2009. Emergency preparedness for higher risk populations: Psychosocial considerations. Radiation Protection Dosimetry 134(3-4): 207-214.

Mahon, A., C. Glendinning, K. Clarke, and G. Craig. 1996. Researching children: Methods and ethics. Children and Society 10(2): $145-154$

McConachie, H., and T. Diggle. 2007. Parent implemented early intervention for young children with autism spectrum disorder: A systematic review. Journal of Evaluation in Clinical Practice 13(1): 120-129.

MCDEM (Ministry of Civil Defence and Emergency Management, New Zealand). 2009. "What's the plan stan"? A teaching resource for New Zealand schools. http://www.Whatstheplan stan.Govt.Nz. Accessed 18 Sept 2013.

MCDEM (Ministry of Civil Defence and Emergency Management, New Zealand). 2013. Including people with disabilities. http:// www.civildefence.govt.nz/.../is-13-13-including-people-with-dis abilities. Accessed 18 Sept 2013.

Mihaylov, S.I., S.N. Jarvis, A.F. Colver, and B. Beresford. 2004. Identification and description of environmental factors that influence participation of children with cerebral palsy. Developmental Medicine and Child Neurology 46(5): 299-304.

Murray, J.S. 2011. Disaster preparedness for children with special healthcare needs and disabilities. Journal for Specialists in Paediatric Nursing 16(3): 226-232.

Mutch, C. 2013. Sailing through a river of emotions: Capturing children's earthquake stories. Disaster Prevention and Management 22(5): 445-455.
Mutch, C. 2014. The role of schools in disaster preparedness, response and recovery: What can we learn from the literature? Pastoral Care in Education 32(1): 5-22.

Odom, S.L., E. Brantlinger, R. Gersten, R.H. Horner, B. Thompson, and K.R. Harris. 2005. Research in special education: Scientific methods and evidence-based practices. Exceptional Children 71(2): 137-148.

Peek, L. 2008. Children and disasters: Understanding vulnerability, developing capacities, and promoting resilience-An introduction. Children, Youth and Environments 18(1): 1-29.

Peek, L., and L.M. Stough. 2010. Children with disabilities in the context of disaster: A social vulnerability perspective. Child Development 81(4): 1260-1270.

Pfeiffer, D. 2001. The conceptualization of disability. Research in Social Science and Disability 2(1): 29-52.

Phillips, B.D., D.S.K. Thomas, A. Fothergill, and L. Blinn-Pike. 2010. Social vulnerability to disasters. New York: CRC Press Boca Raton.

Priestley, M. 1998. Childhood disability and disabled childhoods: Agendas for research. Childhood 5(2): 207-223.

Priestley, M., and L. Hemingway. 2007. Disability and disaster recovery: A tale of two cities. Journal of Social Work in Disability and Rehabilitation 5(3-4): 23-42.

Redlener, I. 2008. Population vulnerabilities, preconditions, and the consequences of disasters. Social Research: An International Quarterly 75(3): 785-792.

Save the Children. 2006. Child rights perspectives in response to natural disasters in South Asia. Kathmandu: Save the Children.

Shakespeare, T., and N. Watson. 1998. Theoretical perspectives on research with disabled children. In Growing up with disability, ed. C. Robinson and K. Stalker, 13-28. London: Jessica Kingsley.

Smith, F., E. Jolley, and E. Schmidt. 2012. Disability and disasters: The importance of an inclusive approach to vulnerability and social capital. Sightsavers. https://www.worldwewant2015.org/ node/287097. Accessed 10 Feb 2015.

Stough, L.M. 2009. The effects of disaster on the mental health of individuals with disabilities. In Mental health and disasters, ed. Y. Neria, S. Galea, and F.H. Norris, 264-276. Cambridge: Cambridge Books Online, Cambridge University Press.

Thomas, C. 2004. How is disability understood? An examination of sociological approaches. Disability \& Society 19(6): 569-583.

Thomson, J.L., and C. Philo. 2004. Playful spaces? A social geography of children's play in Livingston, Scotland. Children's Geographies 2(1): 111-130.

Tierney, K.J., J.P. William, and H. Hahn. 1988. Disabled persons and earthquake hazards. Colorado: University of Colorado Boulder, Institute of Behavioral Science.

Turnbull, H.R., G. Beegle, and M.J. Stowe. 2001. The core concepts of disability policy affecting families who have children with disabilities. Journal of Disability Policy Studies 12(3): 133-143.

UNCRPD (United Nations Convention on the Rights of Persons with Disabilities). 2006. Convention on the rights of persons with disabilities and optional protocol. http://www.Un.org/disabilities/ documents/convention/convoptprot-e.Pdf. Accessed 18 Dec 2013.

UNICEF (United Nations Children's Fund). 2007. Promoting the rights of children with disabilities. Florence: UNICEF Innocenti Research Center.

UNICEF (United Nations Children's Fund). 2010. Humanitarian action: Partnering for children in emergencies. Geneva: UNICEF.

UNISDR (United Nations International Strategy for Disaster Reduction). 2013. Living with disability and disaster. http://www.Un. org/disabilities/documents/reports/iddr2013panelreport. Accessed 16 Feb 2014.

Watson, N. 2012. Theorising the lives of disabled children: How can disability theory help? Children and Society 26(3): 192-202. 
Watson, N., A. Roulstone, and C. Thomas. 2012. Routledge handbook of disability studies. New York: Routledge.

WHO (World Health Organization). 2007. The world health report 2007-A safer future: Global public health security in the 21st century. Geneva: World Health Organization.

Wisner, B. 2002. Disability and disaster: Victimhood and agency in earthquake risk reduction. RADIX. http://online.northumbria.ac. uk/geography_research/radix/resources/disability_and_disaster_ wisner.doc. Accessed 10 May 2014.

Wisner, B. 2006. Let our children teach us. A review of the role of education and knowledge in disaster risk reduction. Geneva: UNISDR System Thematic Cluster/Platform on Knowledge and Education.
Wisner, B., P. Blaikie, T. Cannon, and I. Davis. 2004. At risk: Natural hazards, people's vulnerability and disasters, 2nd edn. London: Routledge.

Wisner, B., J.C. Gaillard, and I. Kelman. 2012. Framing disaster: Theories and stories seeking to understand hazards, vulnerability and risk. In Handbook of hazards and disaster risk reduction, ed. B. Wisner, J.C. Gaillard, and I. Kelman, 18-34. London: Routledge.

Woodhouse, B. 2004. Re-visioning rights for children. In Rethinking childhood, ed. P.B. Pufall and R.P. Unsworth, 229-243. New Jersey: Rutgers University Press. 